\title{
Mercury A Dilemma for the Caribbean Region
}

\author{
Terry I Mohammed*1 and Azad Mohammed ${ }^{2}$ \\ ${ }^{1}$ Department of Chemistry, the University of the West Indies, St. Augustine Trinidad and Tobago \\ ${ }^{2}$ Department of life science, the University of the West Indies, St. Augustine Trinidad and Tobago
}

Received: May 05, 2018; Published: May 21, 2018

*Corresponding author: Terry I Mohammed, Department of Chemistry, the University of the West Indies, St. Augustine Trinidad and Tobago

\begin{abstract}
The islands of the Caribbean have long been susceptible to the impact of Mercury pollution. Factors such as consumption of contaminated fish, usage of mercury based cosmetic products, artisanal gold mining activities and poor disposal and handling of mercury containing equipment and products are significant sources of Mercury with entry into the human body via ingestion, inhalation and absorption through the skin and membranes. Geographically, the region is located where a number of oceanic currents converge, bringing with it pollution from Western Europe, West Africa and South America. The region is therefore strongly influenced by external sources of Mercury. Although these island states cannot influence the externally generated mercury pollutants, they can at least take charge of the internally generated pollutants. As these islands attempt to implement the guidelines of the Minamata Convention, some of the sources of Mercury in the region are explored along with the challenges they face developing and implementing these new policies.
\end{abstract}

Keywords: Mercury; Caribbean; Uses of Mercury; Minamata Convention; Mercury Pollution

\section{Introduction}

The element Mercury has been around for a very long time. It is not sure who discovered it or how it was discovered, but it was well known by the ancients and widely used by modern man. The symbol for Mercury is $\mathrm{Hg}$, which is short for hydrargyrum [1], Latin for liquid silver. Mercury is a heavy element that conducts heat fairly well and electricity very well. In its elemental state it is relatively inert, it does not react with strong acids and has the uncanny ability for staying together, on the other hand, Mercury in its vapor state is very toxic [2].

\section{The Toxicity of Mercury}

Mercury have been known to cause a range of health issues including damage to the central nervous system, neurological and behavioural disorders, tremors, insomnia, memory loss, neuromuscular effects, headaches, corrosive to the skin, eyes and gastrointestinal tract, can induce kidney toxicity if ingested and at times can be fatal [3]. The toxicity of Mercury is dependent on its chemical form, dose and rate of exposure with Mercury in some chemical forms being more toxic than others. Inorganic Mercury constitutes Mercury salts, elemental Mercury and Mercury vapour. Mercury vapour, which is a common source of exposure for artisanal gold miners, is rapidly absorbed through the mucus layer of the pulmonary tract at a rate of $80 \%$, with at least $66 \%$ of the absorbed Mercury transported immediately in the blood to various organs and tissue [4]. As only 3\% of the Mercury vapour is oxidized between the lung and brain [5], the majority of Mercury reaches the brain in the form of the vapour which easily crosses the blood-brain barrier [6], leading to severe neurological disorders.

Inorganic Mercury in the form of Mercury salts such as those used in skin bleaching creams are absorbed via the intestinal tract and affect many organs in particular the kidneys resulting in nephrotic syndrome and organ failure. Other conditions include Contact Dermatitis and Acrodynia (painful extremities) [3]. Organic Mercury, typically Ethyl and Methyl Mercury are commonly found in larger fishes and can be easily absorbed through the skin and intestines and deposited in tissues, however organic Mercury does not cross the blood-brain barrier as quickly as Mercury vapour. Methyl Mercury subsequently does concentrate in brain tissue by forming MeHg-L-cysteine complex, which mimics the molecular structure of Methionine [7]. Methyl Mercury is therefore responsible for severe neurological disorders with symptoms similar to those caused by Mercury Vapour. The same cannot be said about Ethyl Mercury which accumulates more in the kidneys than the brain [8] resulting in a prevalence of nephrotic syndrome and organ failure.

\section{Common uses of Mercury in the Caribbean Region}

In spite of Mercury's bad reputation and toxic nature, its use is widespread in the modern world and by extension the Caribbean 
Region, and this is due to Mercury's unique properties. Among the more popular uses of Mercury is its use in thermometers and barometers [9]. Mercury is the only metal that is a liquid at room temperature and it is used in thermometers because it has both high and linear coefficient of expansion. Hence, the slightest change in temperature results in a significant volumetric expansion. Mercury also has a low vapour pressure so it is relatively safe to use in sealed thermometer tubes, at least up to $356.73^{\circ} \mathrm{C}$ which is the boiling point of Mercury. Mercury thermometers and even disposable Mercury thermometers are still being used in the Caribbean Region and are still sold and distributed by marketing companies [10].

Mercury is used in barometers and sphygmomanometers because it is the densest liquid known, requiring only $760 \mathrm{~mm}$ of Mercury to indicate atmospheric pressure, and only a few $\mathrm{cm}$ to measure blood pressure [9]. Water on the other hand would require 39 feet to indicate the same pressure. The use of Mercury based barometers and sphygmomanometers in the region have reduced significantly as the digital alternatives are lower priced and easier to use. Mercury based electrical switches and relays have been used up until 2003 when they were still being produced and in use in some areas [11]. Many users of larger scale industrial Mercury based switches have phased these out in favour of modern more reliable alternatives.

Compounds of Mercury as well as the vapours are commonly used in Fluorescent Light Bulbs [12]. Fluorescent bulbs produce light when an electric current passes between two electrodes or cathodes in a tube filled with Mercury vapour and inert gases, such as argon and krypton under a low-pressure. The Mercury vapour in the tube is excited by an electric current, generating radiant energy. The energy causes a phosphor coating on the inside of the tube to "fluoresce" and produce light. Mercury is present in the lamp in both the phosphor powder and in the vapour [13]. Very often these Mercury lamps including Compact Fluorescent Lamps (CFL's) find their way into domestic landfills where the Mercury from these lamps leach into ground water, rivers and streams [14]. The regional drive towards reducing energy costs have led to a significant number of homes, offices and businesses switching from conventional light bulbs to fluorescent and compact fluorescent light bulbs.

The Ministry of Energy and Energy Affairs Trinidad and Tobago have launched a "Light Bulb Exchange Initiative in 2015 [15], where incandescent bulbs can be switched to compact florescent bulbs. However, without a national program for the disposal of these fluorescent light bulbs, many of them are disposed of in the domestic landfills. It is estimated that up to 50 million Compact Florescent Lightbulbs (CFL) have been imported into the region, and with each bulb containing up to $3.6 \mathrm{mg}$ of Mercury [16], an estimated $180 \mathrm{~kg}$ of Mercury have the potential of ending up in domestic landfills. Caribbean states that have signed and ratified the Minamata Convention are required to eliminate these sources of Mercury by 2020 [17]. In most cases, this is the only regulation governing Mercury and its usage in the region.
Mercury is commonly used in Dental Amalgams. Dental Amalgam is a silver-colored material used to fill cavities in teeth. Dental amalgam is made of two nearly equal parts: liquid Mercury and a powder containing silver, tin, copper, zinc and other metals [18]. Amalgam is one of the most commonly used tooth fillings, and is considered to be a safe, sound, and effective treatment for tooth decay [19]. The chemical properties of elemental Mercury allow it to react with and bind with silver/copper/tin alloy particles to form an amalgam. The amalgam starts off with the consistency of putty and fills the gaps in the tooth. It eventually hardens and becomes wear resistant. Amalgams are very common in the practice of dentistry in the Caribbean region. Up to $50 \%$ of dentists have confirmed that they dispose of Mercury containing amalgams in the regular trash and another $40 \%$ wash theirs down the sink [20]. Dental amalgams therefore contribute significantly to the Mercury burden of the region.

Elemental Mercury is commonly used to extract gold in gold mining [21]. Mercury forms an amalgam with gold and not the other rock components, thus allowing fine particles of gold to be separated from sand and dirt. By heating the amalgam to a temperature above the boiling point of Mercury $\left(356.73^{\circ} \mathrm{C}\right.$ ), Mercury boils off, leaving pure gold. The Mercury vapours enter the atmosphere where they deposit in forests, rivers and oceans. This process is commonly used in many gold producing countries through Latin America [22] including Guyana, Suriname and Venezuela, and Mercury's use is generally unregulated particularly in artisanal mines. Mercury emissions form artisanal mines is among the largest contributor to the global Mercury burden [23]. Although government regulations may be dictated by the Minamata Convention, implementation of regulations may be a challenge as these artisanal mines make a significant contribution to the GDP of some regional states and are generally unregulated. Mercury's toxicity is a "double edged sword". Although it is toxic to human health, it is also toxic to bacteria and fungus. As a result, Mercury was and still is commonly used as a fungicide in agriculture [24], to preserve seeds and wood [25], a component in mold resistant paints [26] and as a preservative in vaccines [27]. Its usage in these fields is now regulated and significantly reduced due to potential toxicity to humans and the availability of less toxic alternatives.

Caribbean nations have reported success in phasing out Mercury based biocides and pesticides [17] and proposals are being implemented to eliminate Mercury based paints by 2020 . Cosmetics and skin-lightening products are one of the most unregulated sectors in the Caribbean [17]. Studies have found that there are significant levels of Mercury in makeup, skin creams, bleaching creams [28] and lipstick in both organic and inorganic forms [29]. This is particularly of concern due to the possibility of ingestion and absorption through the skin. While some available skin-lightening creams produced in Jamaica, West Africa and India have labels that indicate the presence of inorganic Mercury compounds many others don't. Additionally, tested products have been found to contain as much as 33,000ppm [30]. Due to the rising popularity of skin bleaching within communities and among local 
celebrities within the region, the use of skin lighteners is in fashion and the risks posed by skin bleaching creams are now higher than ever.

\section{Challenges of the Region}

Mercury containing products includes electrical switches and relays, batteries, lighting devices, medical devices, pesticides and cosmetics. While some of the Mercury in these products can be collected and recycled, the feasibility of such measures may be greatly reduced. A lack of enforced regional and state regulations is the main hindrance for the elimination of Mercury in the region. Some of the island states do have regulatory limits for Mercury in the environment but very few have enacted regulation governing Mercury in consumer products, food and cosmetics. Such regulations are the "first line" of defense for populations that may be at risk. Manufacturers are not required to list all of the components of their products and this leaves users and disposers unaware of the need for special disposal.

A lack of efficient collection and disposal systems and a lack of storage and recycling facilities all hinder recycling efforts. Public awareness is also a significant challenge as the public remains unaware of the hazards of using Mercury based products and the appropriate disposal of these products. Although recycling facilities are few in the region, they do exist on some islands. The general public are not aware of their existence and recycling comes as a cost to the consumer which also provides a hindrance to regulatory efforts. At this point in time, recycling of Mercury containing products are entirely voluntary since regulations limiting or eliminating the use of such products do not exist. The signing and ratification of the Minamata Convention by the island states that make up the Caribbean region is the first step in a long journey to eliminate Mercury from the region.

\section{References}

1. Webster N (1942) Webster's New Twentieth Century Dictionary of the English Language: Being the Unabridged Dictionary: Publishers Guild.

2. Haynes WM (2016) CRC handbook of chemistry and physics.

3. Magos L, Clarkson TW (2006) Overview of the clinical toxicity of mercury. Annals of clinical biochemistry 43(4): 257-268.

4. Kudsk FN (1965) Absorption of mercury vapour from the respiratory tract in man. Basic \& Clinical Pharmacology \& Toxicology 23(2-3): 250262.

5. Hursh J, Sichak S, Clarkson T (1988) In vitro oxidation of mercury by the blood. Basic \& Clinical Pharmacology \& Toxicology 63(4): 266-273.

6. Magos L, Clarkson TW, Hudson AR (1989) the effects of dose of elemental mercury and first-pass circulation time on exhalation and organ distribution of inorganic mercury in rats. Biochimica et Biophysica Acta (BBA)-General Subjects 991(1): 85-89.

7. Magos L, Clarkson TW, Hudson AR (1989) the effects of dose of elemental mercury and first-pass circulation time on exhalation and organ distribution of inorganic mercury in rats. Biochimica et Biophysica Acta (BBA)-General Subjects 991(1): 85-89.

8. Simmons Willis TA, Koh AS, Clarkson TW, Ballatori N (2002) Transport of a neurotoxicant by molecular mimicry: the methylmercury-L-cysteine complex is a substrate for human L-type large neutral amino acid transporter (LAT) 1 and LAT2. Biochemical Journal 367(Pt 1): 239-246.
9. Magos L, Brown A, Sparrow S, Bailey E, Snowden R, et al. (1985) The comparative toxicology of ethyl-and methylmercury. Archives of toxicology 57(4): 260-267.

10. Ramanathan E (2006) AIEEE Chemistry: Sura Books.

11. (2018) Disposable Mercury Thermometer 12 per box.

12. W Shen, R Edwards, CJ Kim (2003) Mercury droplet micro switch for reconfigurable circuit interconnect. TRANSDUCERS pp. 464-467.

13. Lim SR, Kang D, Ogunlseitan OA, Schoenung JM (2012) Potential environmental impacts from the metals in incandescent, compact fluorescent lamp (CFL), and light-emitting diode (LED) bulbs. Environmental science \& technology 47(2): 1040-1047.

14. Branch UC (2010) Toolkit for identification and quantification of mercury releases. UNEP chemicals branch, mercury programme.

15. Aucott M, McLinden M, Winka M (2003) Release of mercury from broken fluorescent bulbs. Journal of the Air \& Waste Management Association 53(2): 143-151.

16. MR Narayane (2015) Renewable Energy Policies in Trinidad and Tobago presented at the Regional Workshop on Metrology and Technological Challenges of Climate Science and Renewable Energy Kingston Jamaica.

17. A Gupta, S Vidyarthi, N Sankararamakrishnan (2014) Enhanced sorption of mercury from compact fluorescent bulbs and contaminated water streams using functionalized multiwalled carbon nanotubes. Journal of hazardous materials 274: 132-14.

18. (2017) BCRC, in Development of Minamata Initial Assessments in the Caribbean (Jamaica, Saint Kitts and Nevis, Saint Lucia, Trinidad and Tobago), National Results Validation Workshops - Summary Trinidad and Tobago.

19. Ferracane JL (2001) Materials in dentistry: principles and applications: Lippincott Williams \& Wilkins.

20. Cartland RF (2011) The US Dental Amalgam Debate, 2010 Meeting of the FDA Dental Products Panel.

21. Paryag Amit, Amrita S Paryag, Reisha N Rafeek, Angelus Pilgrim (2010) Mercury Pollution from Dental Amalgam Waste in Trinidad and Tobago. Journal of Water Resource and Protection JWARP, no. 2 (8): 762-769.

22. Veiga MM (1997) Mercury in artisanal gold mining in Latin America: facts, fantasies and solutions. Paper presented at the UNIDO-Expert Group Meeting-Introducing New Technologies for Abatement of Global Mercury Pollution Deriving from Artisanal Gold Mining, Vienna, Austria.

23. Veiga MM, Maxson PA, Hylander LD (2006) Origin and consumption of mercury in small-scale gold mining. Journal of cleaner production 14(34): 436-447.

24. Michael A, Irene A (2004) Handbook of Preservatives. Synapse Information Resources Inc., Endicott, NY, USA.

25. Mathre D, Johnston R, Grey W (2001) Small grain cereal seed treatment. The Plant Health Instructor.

26. Agocs M, Etzel RA, Parrish RG, Paschal DC, Campagna PR, et al. (1990) Mercury exposure from interior latex paint. New England journal of medicine 323(16): 1096-1101.

27. Pichichero ME, Gentile A, Giglio N, Umido V, Clarkson T, et al. (2008) Mercury levels in newborns and infants after receipt of thimerosalcontaining vaccines. Pediatrics 121(2): e208-e214.

28. Mohammed T, Mohammed E, Bascombe S (2017) The evaluation of total mercury and arsenic in skin bleaching creams commonly used in Trinidad and Tobago and their potential risk to the people of the Caribbean. Journal of public health research 6(3): 1097.

29. Sin K, Tsang H (2003) Large-scale mercury exposure due to a cream cosmetic: community-wide case series. Hong Kong Medical Journal 9(5): 329-334.

30. (2011) WHO, mercury in skin lightening products. 
(C) (i) This work is licensed under Creative Submission Link: https://biomedres.us/submit-manuscript.php

$\begin{array}{ll}\text { BIOMEDICAL } & \text { Assets of Publishing with us } \\ \text { RESEARCHES } & \text { - Global archiving of articles } \\ \text { - Immediate, unrestricted online access } & \text { - Rigorous Peer Review Process } \\ & \text { - Authors Retain Copyrights } \\ \end{array}$

